\title{
Análise crítica da cobertura da previsão do tempo em portais especializados
}

\section{Critical analysis of the weather forecast coverage in specialized portals}

María Luisa Sánchez Calero ${ }^{1}$ 


\section{Resumo}

O objetivo desta pesquisa é analisar as tendências e o posicionamento que a informação meteorológica adquire em sites especializados. $\mathrm{O}$ artigo mostra as características de nove portais meteorológicos, com forte presença dos sites espanhóis, dos quais foram analisados aspectos como o discurso que emitem, a linguagem e o vocabulário utilizados, os tipos de fontes consultadas, a organização dos conteúdos, os sistemas de busca, o material gráfico e visual, os sistemas de alerta e as possibilidades de interação dos usuários. Foi requerida na amostra deste estudo a elaboração de um questionário enviado a 400 usuários dessas páginas a fim de conhecer o perfil dos que consultam essas informações na internet, além da análise de 30 websites, públicos e privados, vinculados a esportes ou lazer, com uma seção proeminente sobre informações meteorológicas. Por último, foram analisados os nove portais específicos de informação meteorológica, identificados como os mais referenciados no estudo anterior de sites relacionados a aspectos de lazer, esporte e atividades ao ar livre.

Palavras-chave

Alertas meteorológicos, portais de informações meteorológicas, websites, previsão do tempo, Aemet.

\section{Abstract}

The objective of this research was to analyze the trends and the positioning that meteorological information acquires in specialized websites. This article shows the characteristics of nine meteorological websites with strong presence in the Spanish meteorological web, analyzing some aspects, such as: their speech, the language and vocabulary used, the types of sources consulted, the content organization, the search systems, graphic and visual material, system alerts, and the possibilities of interaction between users. A questionnaire, sent to 400 users of these portals, was required in the sample of this study, in order to know the profile of those who consult these information on the Internet, as well as the analysis of 30 public and private websites linked to sports or leisure that have a prominent section on meteorological information. And finally, the analysis of nine specific portals of meteorological information, identified as the most referenced in previous study of websites related to leisure, sport and outdoor activities.

\section{Keywords}

Meteorological alerts, meteorological information, portals of meteorological information, weather forecast, AEMET. 
Eventos recentes relacionados a fenômenos climáticos adversos mais uma vez destacaram a importância, na sociedade atual, do tempo, do clima ou da água, que se estabeleceram como elementos de especial importância no condicionamento da vida das pessoas e na sua influência no desenvolvimento socioeconômico e ambiental. Observa-se com crescente frequência como a informação meteorológica ocupa muitas das capas da mídia, adquirindo destaque, inclusive, nos resumos de abertura das notícias espanholas. A meteorologia foi um fenômeno de grande interesse em diversas épocas da humanidade e no momento continua sendo uma questão relevante para muitos setores da opinião pública e, portanto, uma das informações mais demandadas. Informações que gradativamente adquirem seguidores com diferentes interesses e que necessitam de canais de informação que se adaptem às necessidades de informação cada vez mais precisas, rigorosas e rápidas.

Essa necessidade implica dar uma resposta informativa que cubra as exigências desses usuários nos meios de comunicação, o que na prática significa fornecer conteúdo em canais e formatos especializados com fontes e sistemas que proporcionam previsões de maior sucesso, mais rigorosas em seus termos, com maior precisão e prazo cada vez mais longo.

A demanda é promovida por um novo perfil de usuário que sente a urgência de ser informado por outros canais de informação mais especializados no ambiente digital, sob a presença de websites privados e institucionais, que incluem a previsão do tempo com a apresentação de códigos e conteúdos mais visíveis que facilitam sua percepção e compreensão com respostas e orientações voltadas às suas próprias necessidades. Portanto, neste artigo, tentamos coletar as características mais gerais e aquelas derivadas de uma investigação baseada em três pilares fundamentais. A primeira análise responde à consulta feita em cerca de 400 pesquisas visando conhecer o perfil dos usuários que consomem informações meteorológicas e verificar a porcentagem daqueles que recorrem aos diferentes websites.

Na segunda parte, foram selecionados cerca de 30 sites e portais públicos e privados espanhóis ligados a aspectos esportivos ou de lazer em que há uma 
seção dedicada à meteorologia em sua área, seja por meio de informações locais ou de um informe anexado a algum site ou portal especializado.

Na terceira parte, foram estudadas as principais características desses portais mais específicos de informações meteorológicas, que foram identificadas como as mais referenciadas na internet em relação aos aspectos de lazer, esporte e atividades ao ar livre. Entre eles se destacam: Meteogalicia, EITiempo.es, TuTiempo. net, Windguru, Tiempo.com, The Weather Channel, Weather Underground, Agencia Estatal de Meteorología (Aemet) e Divulgameteo².

O objetivo do estudo foi salientar os sites que têm melhores informações sobre o tempo para o público e quais são os destaques em cada um deles. Como objeto de análise, diferentes segmentos foram estudados: a linguagem utilizada e o vocabulário, as fontes consultadas, a organização dos conteúdos por seções e subseções, os sistemas de busca, o material gráfico que eles incorporam, o uso de sistemas de alerta, o tratamento da informação - avaliando se é mais ou menos elucidativa -, as possibilidades de interação com os usuários, a publicidade que inserem e o arcabouço legal apresentado pela internet.

\section{Novos interesses, novos canais, novos conteúdos das informações meteorológicas na web}

O aumento do interesse e uma maior demanda por informação meteorológica por parte de públicos muito diversos atualmente justificam o aumento de espaços meteorológicos e uma maior presença desse tipo de conteúdo na rede, adaptado aos benefícios e necessidades de que requisitam os novos públicos com novos propósitos em seus processos e em seu uso e destinado a outros campos de interesse.

Esse conteúdo exige nova identidade, sob a presença de canais, espaços e formatos adaptados ao seu novo uso na rede, a fim de apresentar essas informações 
meteorológicas de maneira veloz e acessível, em tempo real, o que se traduz em transmitir, com rapidez e interatividade, elementos multimídia e uma linguagem mais adaptada aos novos suportes, e que também apostem em soluções eficazes capazes de divulgar correta e facilmente nos termos apropriados.

A presença de novos canais e formatos estão permitindo maior divulgação de dados meteorológicos que enfrentam novas mudanças e hábitos de consumo de novas plataformas, que geram novos modelos de negócios e que canalizam essa informação para modelos mais rentáveis distribuídos em várias partes do mundo.

\section{Linguagem e vocabulário usado}

A mensagem do tempo, na opinião de muitos dos profissionais que reportam o assunto, deve obedecer a uma série de características básicas: clareza e concisão, rigor e honestidade - marcando as diretrizes de um conteúdo fundamentado -, conseguir definitivamente que a informação se torne a protagonista e que o aspecto tecnológico não reduza o protagonismo do mapa meteorológico. É uma comunicação cujas dificuldades lexicais e conceituais constituem um dos principais fatores para a incompreensão dos textos, mas especialistas estão cada vez mais conscientes da importância de adaptá-la ao meio apropriado para que o usuário a entenda.

Neste artigo, realizamos uma análise por meio de nove portais específicos de informações meteorológicas - identificados como os mais referenciados em análise anterior a partir de cinquenta websites espanhóis voltados para atividades de lazer, esportes e atividades ao ar livre. Os sites selecionados são: Meteogalicia, EITiempo.es, TuTiempo.net, Windguru, Tiempo.com, The Weather Channel, Weather Underground, Aemet e Divulgameteo. O objetivo do estudo foi determinar, com diferentes abordagens, aqueles que melhor aproveitam as características da internet para apresentar informações meteorológicas ao público e quais são os aspectos mais relevantes em cada um deles. Entre os elementos que fizeram parte da análise estão: a mensagem apresentada, a linguagem e o vocabulário utilizados para saber o modo como o conteúdo é transmitido em cada um dos 
portais da amostra. Para completar alguns aspectos qualitativos dessas informações, impossíveis de descobrir pela análise funcional, também decidimos entrar em contato com os responsáveis pelos portais meteorológicos espanhóis.

Uma das principais diferenças entre esses portais é encontrada em suas homepages, uma vez que cada um apresenta as informações de clima de acordo com suas próprias características comerciais. Isso é notável, já que a maioria deles não tem textos informativos em sua página principal, sendo dominados por elementos visuais: gráficos, imagens, ícones, tabelas e publicidade exagerada, proporcionando às vezes uma sensação de desordem em alguns deles, como no exemplo de TuTiempo.net. No entanto, em outros, informações detalhadas e completas aparecem no "serviço de pagamento"; se incluem aí certos portais, como o norte-americano Windguru ${ }^{3}$, no qual, ao se pagar uma taxa anual de 19 euros, é possível acessar muito mais conteúdo específico. Enquanto isso, em outros portais, como Meteogalicia, Tiempo.com, Aemet ou ElTiempo.es, encontramos na homepage a presença de textos que incluem detalhes sobre as informações por meio de um resumo da previsão do dia e algumas seções com textos curtos e explicação detalhada e planejada - seções que usam linguagem apropriada, em termos e expressões de fácil compreensão sem cair no uso excessivo de termos técnicos e científicos, além de incluir links que nos direcionam a dados mais específicos sobre o assunto. Assim, é importante destacar que em quase todos os portais a presença de textos escritos é escassa ou está em seções secundárias, e sua presença na homepage é praticamente irrelevante. Existem exceções, como a segmento de "blog" de autoria de José Antonio Maldonado, diretor do ElTiempo. es. Também no site da Aemet encontramos seções, como "notícias" ou "espaço informativo", nas quais aparecem textos escritos corretamente, com explicações tempo deu um salto para as estações de rádio. Depois de algumas transmissões experimentais na década de 1930, a rede WNBC-TV começou a oferecer, em 1941, informações de clima transmitidas aos moradores de Nova York, e sua entrada na televisão se tornou um sucesso (BINKLEY, 1999). 
compreensíveis e úteis - mas, em ambos os casos, eles são muito curtos, logo apresentando o link correspondente para as informações detalhadas. Em outros, como Meteogalicia, observa-se uma descrição minuciosa do escopo geográfico de influência. Usam uma linguagem voltada para público muito específico, nesse caso, o galego. É uma maneira muito direta e clara de ter empatia com os usuários que estão relacionados ao uso do site e de tentar garantir sua lealdade.

\section{As fontes consultadas}

Os informes meteorológicos fornecidos na maior parte dos sites consultados não aparecem como fontes primárias, pois são poucos os organismos que dispõem dos meios técnicos necessários para se tornarem geradores de informação. Ou seja, eles são uma etapa intermediária para facilitar e adaptar conteúdos de fontes primárias a possíveis usuários finais, sejam eles entidades públicas ou privadas, outros sites de meteorologia ou indivíduos. Apenas em dois dos nove portais analisados encontramos alguma referência explícita às fontes utilizadas, EITiempo.es e Aemet. No primeiro, as fontes que aparecem são o próprio portal como observador de conteúdos, e na página da Aemet a fonte é ela mesma e seus próprios sistemas de dados. No resto dos portais, as fontes não aparecem, seja porque são suas próprias informações ou porque não querem ou não Ihes interessa revelá-las por qualquer motivo.

\section{A organização dos conteúdos (seções e subseções)}

A organização do conteúdo é essencial para o sucesso de um site e, portanto, a distribuição de suas seções e subseções deve ser clara, representativa e aparecer de forma ordenada por critérios lógicos, com um bom planejamento que normalmente requer vários ciclos de testes e reestruturações.

É importante destacar, dessa maneira, que a qualidade e profundidade de todos esses conteúdos variam de um portal para outro, como mostra a apresentação de suas páginas e as informações nelas contidas. O contraste entre a diversidade de informações e o rigor da página da Aemet é visível, com a evidente falta 
de outras mídias, como TuTiempo. net ou Meteogalicia, embora seja observada evolução notável. No caso dos mais fracos, seu principal objetivo é a diferenciação, que consiste em encontrar pelo menos um ponto em que possam se destacar dos demais concorrentes e, a partir daí, tentar capturar e manter seus usuários, fazendo uso dessas armas. Em Meteogalicia fica claro, por exemplo, que seu ponto forte é a especialização em toda a informação meteorológica que detalha aspectos de previsões do tempo na costa galega. No Windguru, a singularidade está na caracterização dos ventos. Em TuTiempo.es, eles aumentam a simplicidade na organização e navegação, com base em uma apresentação gráfica cuidadosa e atraente.

Na apresentação de outros portais, como EITiempo.es, TuTiempo.net, Divulgameteo ou Tiempo.com, eles optam pelo uso de uma barra superior com abas para delimitar de forma muito precisa e visual quais seções estão incluídas no seu site. Outros, como a Aemet, usam essa barra no lado esquerdo da página para localizar os links de diferentes seções. Outro sistema mais clássico, mas visualmente eficaz, é o do Meteogalicia, que faz uso de ícones para mostrar as seções, acompanhados por um texto de esclarecimento (nesse caso, em galego) para evitar confusão. Às vezes, alguns desses sites pecam no acúmulo de elementos gráficos com um design pouco coeso que não se encaixa bem, como mostrado por Weather Underground, causando uma sensação de desordem e confusão no usuário, ao mesmo tempo em que incomoda a navegação. De qualquer forma, a experiência mostra que os portais norte-americanos têm, em geral, designs muito mais ornamentados e complexos que os espanhóis. Seus usuários estão mais acostumados com as consultas e, portanto, o que para os espanhóis pode parecer um distúrbio informativo, para os norte-americanos pode ser simplesmente uma aglomeração de dados acessíveis de forma rápida e direta.

Pudemos apreciar neste estudo que a maioria dos sites analisados divide seu conteúdo em algumas seções, mas de modo bem pensado, como observamos em Aemet ou EITiempo.es, em um design organizacional que poderíamos definir 
como minimalista. Outros, como Windguru, no entanto, apresentam uma infinidade de seções e subseções da primeira tela que dão uma noção de barroco não recomendada se quisermos facilitar a interação dos usuários. É claro que a abundância e a variedade de conteúdo são pontos positivos em qualquer portal especializado, mas é preciso saber como administrar sua presença na tela para evitar cansar os usuários do site.

Também podemos encontrar outras seções categorizadas como previsíveis e compartilhadas entre diferentes portais, como "previsão", "galeria de imagens" ou "fotos", "avisos", "mapas meteorológicos" e "fóruns". Além disso, em certos casos há outras abas que podem ser surpreendentes, já que sua relação com a informação meteorológica é bastante tangencial: "astronomia e viagens" (em TuTiempo.net), "terra e esqui" (em Tiempo.com) ou "caminho de Santiago" (em Meteogalicia). Talvez isso possa ser tomado como uma tentativa de diferenciação em relação à concorrência, cada vez mais numerosa e poderosa, mas a presença dessas abas nem sempre é justificada de forma clara.

Algumas seções, como "blogs", e a interação do usuário por fotografias e vídeos estão crescendo em muitos dos sites analisados. No caso do ElTiempo. es, o blog se torna parte fundamental do portal, já que é o mecanismo de interação direta entre seu diretor, José Antonio Maldonado, e os usuários, com o blog do meteorologista Mario Picazo recentemente incorporado. Os portais norte-americanos analisados são, pelo contrário, menos inclinados a incluir esse tipo de seção interativa; seu objetivo é, acima de tudo, oferecer um serviço de informação rápido e preciso. A interação participativa e criativa dos consumidores requer tempo e esforço que a maioria dos usuários, pelo menos o que parece ser deduzido do ponto de vista norte-americano, não está disposta a empregar. A exceção é o Weather Underground, que oferece uma aba muito completa de blogs e a possibilidade de incluir e comentar em fotografias. Outros, como o AccuWeather (Espanha) ${ }^{4}$, são muito simples e têm poucas seções. 


\section{Sistemas de pesquisa}

Uma das ferramentas fundamentais nas páginas da web são os sistemas de busca, especialmente naquelas que atingem dimensão e certo nível de complexidade. Os portais possuem mecanismo de busca para ajudar o usuário a localizar alguns elementos de maneira rápida e eficiente. Em nosso estudo, apenas o Meteogalicia não possui esse sistema, enquanto o restante oferece mecanismos de busca mais ou menos completos que facilitam a detecção de conteúdo específico. Entre os sistemas mais fáceis encontrados estão os de ElTiempo.es, Divulgameteo e Tiempo. com, que consistem em uma busca elementar por localização. Nem em Aemet existe uma pesquisa avançada, embora nesse caso a busca permita procurar livremente por um termo que o utilizador escreva, significando um pouco mais de flexibilidade para poder incluir no campo de procura qualquer palavra-chave relacionada ou não ao escopo geográfico e que possibilite um rastreamento mais sintonizado.

Em outros, pelo contrário, filtros de pesquisa variados e detalhados são incluídos e estão localizados em um local preferido dentro da página principal, como em Windguru, o que nos permite tomar decisões para limitar os resultados a horas específicas do dia, mostrar o mapa ou não, atividades esportivas associadas à localidade e muitas outras opções. Também em Weather Underground encontramos um sistema muito completo, que nos permite pesquisar por códigos de aeroportos, estações meteorológicas pessoais, em blogs etc. Em geral, são os portais norteamericanos analisados que incluem sistemas de busca mais poderosos e precisos. Isso mostra que são projetados especificamente para usuários mais experientes e que exigem uso mais intensivo das ferramentas de pesquisa.

Embora não seja o sistema mais comum, alguns portais, como The Weather Channel e TuTiempo.net, conectam seus mecanismos de busca diretamente ao mecanismo de pesquisa genérico Google. Não é muito profissional ou inteligente, do ponto de vista da retenção e lealdade dos usuários, que nossos mecanismos de busca levem a páginas externas na internet. Por esse motivo, tal tipo de solução é geralmente evitado, a menos que, por algum motivo, elas sejam a única opção viável. 


\section{Material gráfico}

Transmitir as informações meteorológicas nos portais utilizando todos os tipos de material gráfico complementar torna-se cada vez mais essencial e eficaz para os destinatários. As características dessa informação complexa na origem, baseadas no tratamento de grande quantidade de dados numéricos, algoritmos sofisticados e estatísticas múltiplas, são adequadas à representação visual. É, portanto, um aspecto que deve ser aproveitado, porque o sucesso de um site desse tipo dependerá em grande parte dela.

Nos portais analisados existem inúmeros elementos gráficos que, em muitos casos, predominam sobre o texto e desempenham papel fundamental na concepção e apresentação da informação. Embora o design e o estilo apresentados nos portais variem muito, podemos dizer que existem duas categorias - que são, de um lado, aquelas que optam por suporte gráfico simples, minimalista e conceitual e, de outro, as que preferem imagens realistas, detalhes máximos e alcançam uma precisão milimétrica nas representações. O primeiro grupo incluiria Meteogalicia, EITiempo.es, Divulgameteo e TuTiempo.net. No segundo, The Weather Channel, Weather Underground e Windguru. Há também, claro, o meio termo, no caso da Aemet, que combina materiais gráficos simples com os mais complexos e realistas. Além disso, eles são muito bem distribuídos, sendo fáceis de localizar pelo usuário.

O tipo de design visual dependerá do público-alvo do portal. Se quisermos chegar ao cidadão comum, possivelmente será melhor optar por um design simples, sóbrio e agradável, como o do ElTiempo.es. Se, por outro lado, estamos mais interessados em informar um tipo muito específico de usuário, como um entusiasta de esportes marítimos, para os quais o vento desempenha papel vital, então vamos optar pelo aprofundamento e detalhamento, com mapas mais complexos, como mostrado em Windguru. Caso o tipo de usuário seja muito variado, teremos que tentar cobrir o máximo e saber coordenar os dois modelos, como na Aemet.

Nos últimos tempos, é cada vez mais comum os portais usarem material gráfico dinâmico em vez das imagens estáticas clássicas. Mas, no momento, nem 
todos têm os meios necessários para incluir e gerenciar esse tipo de sistema visual com facilidade. Por exemplo, em ElTiempo.es, TuTiempo.net e Tiempo.com as imagens fixas ainda predominam. Em outros, como na Aemet e no The Weather Channel, representações visuais foram estabelecidas com progressão dinâmica e, graças às melhorias na largura de banda, podem ser manipuladas todos os dias com maior agilidade em qualquer tipo de dispositivo.

Outros tipos de imagens que aparecem em todos os portais e se tornam um elemento básico da informação meteorológica são as do satélite, indispensáveis hoje, mesmo se nos voltarmos para um público menos especializado, porque se tornaram genéricas graças a sua presença na televisão. Assim, as imagens fornecidas pelo conhecido satélite Meteosat são frequentes, mas há também as do satélite Geostationary Operational Environmental Satellite (Goes), da National Oceanic and Atmospheric Administration (Noaa) ${ }^{5}$.

Uma das vantagens da internet, no que diz respeito a outras mídias, como a televisão, é que o espaço da informação é relativamente mais barato. Desse modo, pode-se incluir maior variedade de materiais gráficos especializados, com informações muito localizadas, precisas e diversificadas, difíceis de obter na imprensa, no rádio ou na televisão. Podemos encontrar mapas de ventos, umidade, dados sobre reservatórios, costas, raios, visibilidade, temperatura da água do mar etc. Escalabilidade, versatilidade e flexibilidade são propriedades profundamente ligadas à rede e muito úteis para novas mídias.

\section{Sistemas de alerta}

A previsão é um dos principais eixos da informação meteorológica. Com o tempo, as ferramentas preditivas melhoraram em precisão e confiabilidade e atualmente esse trabalho pode ser feito com maiores garantias do que no passado. Citando Mariano Medina (1964, p. 34), pioneiro homem do tempo na Televisión Española (TVE), disse que 
un pronóstico del tiempo no sale de una bola de cristal. Sale de muchos miles de observaciones hechas simultáneamente cada tres horas, en todas las partes del mundo. Se apoya sobre la labor de los observadores y de otras personas que se ocupan de transmitir, recibir y retransmitir a su vez las citas de miles de mensajes cifrados.

Entre todos os fenômenos meteorológicos que podem ser antecipados, é relevante para a sociedade prever e comunicar aqueles que têm risco potencial à população. Como acontece na televisão, em portais meteorológicos torna-se cada vez mais necessário divulgar essas situações, fundamentalmente adversas, conhecidas como "alertas" ou, em alguns casos, "avisos".

Entre os portais de nossa análise, a maioria - sete - tem um sistema de comunicação de alerta. Os alertas, no método que geralmente é seguido na Espanha, são divididos em quatro graus ou níveis de risco e quatro cores são normalmente representadas: verde, amarelo, laranja e vermelho. Verde indica que nenhum risco meteorológico está previsto. Amarelo implica um risco potencial que, mesmo que não afete toda a população, pode fazê-lo a atividades específicas; com esse alerta devemos estar atentos e bem informados da evolução atmosférica. Laranja significa um risco importante e perigoso - nesse caso, fenômenos meteorológicos incomuns seriam previstos, no que diz respeito à sua regularidade de ocorrência, em cuja excepcionalidade reside o perigo. Em uma dessas situações, as recomendações das autoridades devem ser seguidas. Finalmente, chegamos ao perigo extremo, representado pelo alerta vermelho. Os danos, sob essa circunstância, afetarão grandes áreas do território e as medidas adotadas serão, em muitos casos, excepcionais.

Essa classificação é usada em portais como Meteogalicia, ElTiempo.es, Tiempo.com e na Aemet. Mas, mesmo na Espanha, há muitos profissionais que falam em especificar ainda mais a categorização dessas cores. Em 23 de março de 2007, por ocasião da celebração do Dia Meteorológico Mundial, o site Meteoalarm6, 
uma iniciativa conjunta da maior parte dos serviços meteorológicos da Europa, foi apresentado oficialmente na cidade de El Escorial, em Madri, permitindo a consulta em tempo real, pela internet, das diversas advertências de clima para a maior parte do território europeu. O uso do mesmo código de cores e a aplicação de critérios de ativação comuns para os diferentes alertas tornam esse serviço uma ferramenta de consulta muito valiosa.

Em outros portais, de natureza mais internacional, segue-se o sistema de representação norte-americano, totalmente diferente do anterior. Os códigos de cor mudam completamente e, portanto, o vermelho significa tornado, o verde perigo de inundação, laranja é calor intenso, cinza é nevoeiro denso e assim por diante. Nos portais The Weather Channel e Weather Underground esse método é usado. É importante ter isso em mente, pois pode-se incorrer em erros de interpretação bastante sérios.

A opinião dos profissionais sobre mapas e gráficos é de que essas cores são úteis para a comunicação de alertas, mas não são suficientes. É necessário acompanhar a informação visual com texto que explica, em detalhe, cada um dos fenômenos que foram previstos e geraram esse alerta. Nesses casos, a linguagem e o estilo são fundamentais, pois devem ser textos muito cuidadosos, que relatam com o maior rigor possível, mas sem provocar alarmes desnecessários à população.

\section{A divulgação das informações}

Meteorologia é uma ciência interdisciplinar que estuda diferentes fenômenos relacionados à física, química, termodinâmica etc. Mas nos últimos tempos a aproximação do público em geral torna necessário que esses fenômenos sejam disseminados pela interpretação e popularização desse conhecimento. A função do disseminador - cientista ou jornalista - é fundamental nessa tarefa, pois atua como ponte indispensável para estabelecer a comunicação entre a fonte especializada e o cidadão comum.

Dos nove portais de informação meteorológica analisados, apenas um, o Windguru, não possui seções específicas para divulgação. Entre os 
outros, descobrimos que existem aqueles comprometidos com a divulgação de informação, enquanto o restante, mais focado na previsão, faz menos esforço com esse fim.

Entre os mais completos, destacaram-se há alguns anos os sites Divulgameteo e o da Aemet. Em ambos, aparecem seções dedicadas exclusivamente a divulgar informações sobre eventos, congressos, conferências etc. relacionados à meteorologia. Também incluem importante compilação de bibliografia e artigos de diferentes autores e casos relacionados ao assunto. Eles ainda trazem para o público fenômenos meteorológicos que são atuais e devem ser explicados com maior profundidade e rigor científico, como ocorreu recentemente, em fevereiro de 2010, com a "ciclogênese explosiva" que afetou grande parte da Península Ibérica e do oeste da França.

Um dos mecanismos cada vez mais presentes na divulgação é o uso de blogs. É comum que portais tenham links para esse tipo de página pessoal, em que um especialista no campo tenta transmitir, a partir de sua experiência profissional, conhecimentos meteorológicos para o público em geral. Um dos trabalhos mais notáveis é feito por José Antonio Maldonado no ElTiempo.es. Em seu blog são bastante frequentes entradas com informações de divulgação, muito bem apresentadas, tratadas e ligadas à atualidade, o que, tendo em vista o número de comentários que suscitam entre os leitores, pode ser considerado um sucesso.

Outro dos elementos de divulgação que aparece com frequência nos portais analisados é o dicionário de termos meteorológicos. Embora seja constituído como o recurso mais simples e primitivo de divulgação, vale a pena incluí-lo lembremos que o espaço é "quase" gratuito na rede - para facilitar ao usuário a busca de termos especializados. Podemos encontrar exemplos desse tipo de dicionário em portais como Meteogalicia e TuTiempo.net.

Tradicionalmente, as revistas especializadas são instrumentos essenciais para divulgação. Com o boom da internet, novas publicações desse tipo surgiram e muitas das que já existiam foram digitalizadas. No portal Tiempo.com essa opção 
interessante não foi esquecida e um link direto para a Revista del Aficionado a la Meteorología $(\mathrm{RAM})^{7}$ foi incluído, na qual podemos encontrar bastante material de divulgação.

Em geral, pode-se dizer que a internet é um meio ideal por causa de suas características de disseminação. A distribuição do tempo e do espaço é muito mais livre do que na mídia tradicional - imprensa, rádio e televisão - e as desculpas usuais sobre essa limitação de recursos não podem mais ser usadas para ignorar ou marginalizar a divulgação.

\section{As possibilidades de interação do usuário}

A internet ultrapassa de longe outras mídias em termos das muitas possibilidades de interação oferecidas aos usuários. Em todos os portais de informações meteorológicas analisados, identificamos diferentes elementos de interação com os consumidores. A única exceção é a Aemet, que, agindo como um centro de referência do Estado, é um caso muito particular, bem mais fechado para o público a esse respeito.

Entre os sistemas de interação mais frequentes nos websites analisados estão os fóruns temáticos. Podemos encontrá-los em TuTiempo.net, Windguru e Tiempo.com. São bastante diversos em seus conteúdos e existem aqueles mais específicos para climatologia, técnicas e instrumentos meteorológicos, natureza e meio ambiente, clima local etc. Quase todos permitem que os usuários interajam livre e naturalmente, desde que cumpram as regras básicas de respeito estabelecidas pelos moderadores.

Outro mecanismo muito estabelecido de interação que se consolidou nos últimos anos é a possibilidade de incluir comentários nas notícias, nos blogs, nas fotografias etc. É uma opção simples, mas muito interessante, pois permite tanto a comunicação com outros usuários quanto com o autor, ou autores, das informações. Além disso, incorpora a possibilidade de medir, de forma bastante 
objetiva, o interesse que um determinado tópico suscitou entre os leitores, de modo a considerá-lo para futuras publicações. Os responsáveis pelo conteúdo desses portais não devem, em hipótese alguma, desperdiçar esse feedback, porque expõe com precisão suficiente seu público real. É necessário, na medida do possível, aproveitar-se disso para melhorar e adaptar seus serviços às demandas dos usuários. Cada vez mais agências dedicadas ao controle de acessos estão surgindo na web e, para a sobrevivência de qualquer site, o crescimento, a fidelidade e a consolidação dos consumidores se tornaram fundamentais para manter um nível que pode ser considerado competitivo.

Ultimamente, aproveitando a força da fotografia digital, tornou-se muito comum que os usuários tenham a oportunidade de publicar suas fotos relacionadas à meteorologia. Seções desse tipo foram incluídas em ElTiempo.es, TuTiempo.net e Weather Underground. É um método que melhora a interação visual e que também abre a porta para a fotografia amadora. Diante de certos fenômenos meteorológicos, fugazes e muito localizados, a contribuição dos documentos audiovisuais dos usuários que presenciaram o evento tornou-se muito importante para a mídia, não apenas na internet. É corriqueiro, nos últimos tempos, ver na televisão gravações de vídeo amadoras que conseguiram capturar uma tempestade impressionante, uma inundação, um tornado e assim por diante.

Poucos portais climáticos se arriscam, no momento, a oferecer sistemas de interação com usuários realmente inovadores. Apenas no The Weather Channel podemos encontrar opções de interação que são raras na Espanha atualmente. Oferece, por exemplo, a possibilidade de bate-papo ao vivo com os meteorologistas ou um tour instrutivo por um estúdio virtual. No entanto, deve-se notar que essas opções só aparecem na versão internacional do site em inglês. Se acessarmos a versão traduzida para o espanhol, teremos apenas algumas opções básicas do portal disponíveis. É provável que todas as seções sejam incorporadas em espanhol no futuro, mas, enquanto isso, essas limitações devem ser levadas em consideração. Hoje, a língua da rede até 
aqui é o inglês e, embora sendo gradualmente incorporada grande quantidade de conteúdo em outros idiomas, ainda é necessário usá-lo como idioma de referência nas pesquisas.

\section{Conclusões}

- Uma das principais funções da mídia é informar o que é necessário para responder às demandas dos usuários. Atualmente, existem várias informações que ocupam as primeiras páginas dos meios de comunicação em muitas ocasiões, e uma que a cada dia atinge papel mais importante nesses meios é a informação meteorológica.

- A frequência e o surgimento de eventos climáticos adversos são atualmente traduzidos em aumento de interesse do público em conhecer tanto o evento em si quanto sua prevenção e alerta. Dos entrevistados neste estudo, $88 \%$ dizem que consultam e usam esse tipo de informação com mais frequência do que alguns anos atrás, ocasionando sua maior presença na mídia adaptada aos benefícios e necessidades que os novos usuários demandam.

- O consumo desse conteúdo está mudando. Nosso estudo mostra que $30 \%$ dos entrevistados disseram que consultam as informações meteorológicas pelos diferentes canais de televisão e outros $40 \%$ o fazem pela internet. Já os restantes $30 \%$ dos entrevistados dizem usar o telefone celular em sua consulta direta.

- Dos $40 \%$ de usuários que costumam consultar a informação meteorológica na web, mais da metade, $51 \%$, optam por fazêlo em portais especializados no assunto. Outros $23 \%$ optam pela imprensa digital e apenas $20 \%$ dos entrevistados optam por portais de conteúdo geral.

- Os portais especializados em informação meteorológica cobrem muitas das lacunas de conteúdo. Sua finalidade é fornecer informes úteis e práticos a fim de oferecer dados mais completos, ricos em fontes e 
melhor organizados. Para isso, alocam maior número de recursos, como blogs. Incluem mecanismos para participação do público e inserem outros elementos úteis, como serviços de alerta.

- O portal mais referenciado como fonte, o que recebe o maior número de usuários, o que mais interessa ao serviço de alerta e aos serviços de informações meteorológicas, é o da Aemet. Observamos que o resto dos portais (Meteogalicia, ElTiempo.es, TuTiempo.net, Windguru, Tiempo. com, The Weather Channel e Weather Underground) se esforça para melhorar certos elementos, como a especialização dos conteúdos, o idioma escolhido, o design ou a figura do especialista de prestígio para diferenciar-se do resto. ElTiempo.es estabelece seu elemento diferenciador no aumento da simplicidade em design e navegação, além de contar com a figura do renomado meteorologista José Antonio Maldonado. Outros, como o Windguru, especializam-se em relatórios de vento. O ponto forte do Meteogalicia é a especialização em todos os assuntos galegos. Em Tiempo.com destaca-se a conexão com a revista RAM, que lhe permite estar em dia com os últimos artigos, reportagens, notícias etc.

- Em todos os sites dedicados ao esporte, lazer e atividades ao ar livre, verifica-se que os portais especializados em informação meteorológica se tornaram um elemento essencial. Eles fornecem conteúdos úteis e de rápido consumo para os usuários da internet, que buscam na rede informações completas para seu uso e que atendam aos seus interesses. Essa colaboração entre os portais e a internet leva a uma popularização dos primeiros, porque muitos usuários entram neles por meio desses sites pela primeira vez.

- Os portais americanos são os mais utilizados para incluir sistemas de busca mais poderosos e precisos. Isso mostra que eles são projetados especificamente para usuários mais experientes e que precisam de um uso mais intensivo de ferramentas de pesquisa. 


\section{Referências}

AMARAL, F.; GIMENO, D. Evolución, tendencias y modelos en el diseño de webs de noticias. Barcelona: Sol 90, 2010.

BINKLEY, M. Television weathercaster. In: MURRAY, M. D. (Ed.). Encyclopedia of television news. Phoenix, Oryx, 1999. p. 276-277.

CEBRIÁN HERREROS, M. Información televisiva: mediaciones, contenidos, expresión y programación. Madrid: Síntesis, 2003.

DÍAZ NOCI, J. La escritura digital. Bilbao: Servicio Editorial de la Universidad del País Vasco, 2002.

EDO, C. Del papel a la pantalla: la prensa en internet. Madrid: Comunicación Social, 2002.

FLEMING, G. Los servicios meteorológicos para el público desde la perspectiva de la prestación de servicios: una visión general. 2008. Disponível em: <https:// bit.ly/2I1Q344>. Acesso em: 10 jan. 2011.

FLORES J.; AGUADO G. Modelos de negocio en el ciberperiodismo. Madrid: Fragua, 2005.

FONT TULLO, I. Climatología de España y Portugal. Madrid: Servicio de Publicaciones del Instituto Nacional de Meteorología, 2000.

MEDINA, M. El tiempo es noticia. Madrid: Cid, 1964. 
Iniciación a la meteorología. Madrid: Paraninfo, 1994.

PARRA D.; ÁlVAREZ J. Ciberperiodismo. Madrid: Síntesis, 2004.

RIOSALIDO ALONSO, R. Un servicio meteorológico eficaz para España. Ambienta, Madrid, n. 85, feb. 2009. Disponível em: <https://bit.ly/2qZ5ZJ3>. Acesso em: 11 jan. 2011.

RIVERA, Á. Una mayor presencia social. Ambienta, Madrid, n. 85, feb. 2009. Disponível em: <https://bit.ly/2FgYGBj>. Acesso em: 10 jan. 2011.

SÁNCHEZ CALERO, M. L. La información meteorológica como servicio. Madrid: Servicio de Publicaciones de Ministerio de Medio Ambiente, 2005a.

. La meteorología y sus intereses en la información de servicio. Razón y Palabra, Atizapán de Zaragoza, n. 45, jun.-jul. 2005b.

La divulgación científica de la meteorología: emisores implicados. Quark, Barcelona, n. 37-38, p. 65-70, sept. 2005-abr. 2006.

SARTORI, G. Homo videns: la sociedad teledirigida. Madrid: Santillana-Taurus, 1997.

TUBAU, I. Periodismo oral: hablar y escribir para radio y televisión. Barcelona: Paidós Ibérica, 1993.

VALLÉE, J.-L. Guía técnica de meteorología. Madrid: Omega, 2006.

WATTS, A. Cómo predecir el tiempo: interpretar las señales. Madrid: Omega, 2008. 
VIÑAS, J. M. La divulgación de la meteorología en la radio española. In: JORNADAS DE LA ASOCIACIÓN METEOROLÓGICA ESPAÑOLA, 30., Zaragoza, 2008. Actas... Madrid: AME, 2008. Disponível em: <https://bit.ly/2HXvYIK>. Acesso em: 12 jan. 2011. . Desinformación meteorológica. Tercer Milenio, Zaragoza, n. 530, feb. 2010. Disponível em: <https://bit.ly/2HOiOA7>. Acesso em: 12 jan. 2011.

ZALCBERG, A. El ciberperiodismo. Estudios sobre el Mensaje Periodístico, Madrid, n. 7, p. 167-184, 2001.

submetido em: 05 abr. 2018 | aprovado em: 03 maio 2018 